\title{
Adaptive feedback analysis and control of programmable stimuli for assessment of cerebrovascular function
}

Lingke Fan ${ }^{*}$, Glen Bush ${ }^{*}$, Emmanuel Katsogridakis", David M. Simpson ${ }^{* *}$, Robert Allen $^{* *}$, John Potter ${ }^{* * *}$, Anthony A. Birch ${ }^{\# \#}$, Ronney B. Panerai ${ }^{\#}$

* Dept of Medical Physics, University Hospitals of Leicester NHS Trust, Infirmary Square, Leicester LE1 5WW, UK

** Institute of Sound and Vibration Research, University of Southampton, Southampton S017 1BJ, UK

*** Ageing and Stroke Medicine Section, University of East Anglia, Norwich NR4 $7 T J, U K$

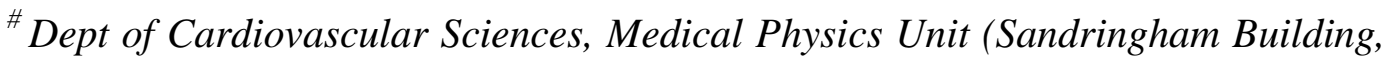
Leicester Royal Infirmary), University of Leicester, Leicester LE1 5WW, UK

\#\# Neurological Physics Group, Department of Medical Physics and Bioengineering, Southampton University Hospitals NHS Trust, Southampton SO16 6YD, UK

Corresponding Author:

Lingke Fan

e-mail: lingke.fan@le.ac.uk

tel: +441162585140

fax: +441162585979

The total number of words of the manuscript, including entire text from title page to figure legends: $\mathbf{4 9 0 5}$

The number of words of the abstract: 180

The number of figures: 6

The number of tables: $\mathbf{2}$ 


\title{
Adaptive feedback analysis and control Page nr. 2 of 19
}

\begin{abstract}
The assessment of cerebrovascular regulatory mechanisms often requires flexiblycontrolled and precisely-timed arterial blood pressure (ABP) and/or $\mathrm{CO} 2$ changes. In this study, a new system for inducing variations in mean $\mathrm{ABP}$ and also to control inhaled $\mathrm{CO}_{2}$ was designed, implemented and tested using programmable sequences and programmable controls to induce pressure changes through bilateral thigh cuffs and also to switch between air and a CO2/air mixture provided via a face mask. Adaptive feedback control of a pressure generator was required to meet stringent specification of fast changes, and accuracy in timing and pressure levels applied by the thigh cuffs. The implemented system consists of a PC-based signal analysis/control unit, a pressure control unit and a $\mathrm{CO}_{2} /$ air control unit. Initial evaluations were carried out to compare the cuff pressure control performances between adaptive and non-adaptive control configurations. Results show that the adaptive control method can reduce the mean error in sustaining target pressure by $99.57 \%$ and reduce the transient time in pressure increases by $45.21 \%$. The system has proven a highly effective tool in ongoing research on brain blood flow control.
\end{abstract}

\section{Keywords}

Dynamic cerebral autoregulation, programmable stimuli, adaptive feedback system, arterial blood pressure control, thigh cuff technique, CO2 reactivity. 


\section{Glossary of Terms}

\begin{tabular}{|c|c|c|c|}
\hline Symbol & Description & Default setting & Unit \\
\hline $\mathrm{ABP}$ & Arterial blood pressure. & NA & $\mathrm{mmHg}$ \\
\hline $\mathrm{EtCO} 2$ & End Tidal CO2. & NA & $\mathrm{mmHg}$ \\
\hline t_0 & $\begin{array}{l}\text { The moment in time at which the ideal } \\
\text { pressure signal changes from "high" to } \\
\text { "low". }\end{array}$ & NA & s \\
\hline $\mathrm{t} \_1$ & $\begin{array}{l}\text { The moment in time at which the ideal } \\
\text { pressure signal changes from "low" to } \\
\text { "high". }\end{array}$ & NA & $\mathrm{s}$ \\
\hline$\Delta \mathrm{t} \_1$ & The cooling period. & 0.4 & $\mathrm{~s}$ \\
\hline $\mathrm{t} \_1 \_1$ & $\begin{array}{l}\text { The moment in time at which the cuff } \\
\text { pressure level reaches } \mathrm{TH} \text { (the threshold } \\
\text { used when state changes from "low" to } \\
\text { "high"). }\end{array}$ & NA & $\mathrm{s}$ \\
\hline t_1_2 & The moment in time at $\mathrm{t}=\mathrm{t} \_1 \_1+\Delta \mathrm{t} \_1$. & NA & $\mathrm{s}$ \\
\hline$\Delta \mathrm{t} \_\mathrm{s}$ & The adaptation period. & 0.1 & $\mathrm{~s}$ \\
\hline t_s_1 & $\begin{array}{l}\text { The moment at which the cuff pressure } \\
\text { level falls and is lower than PTC }-\Delta \text { pe. }\end{array}$ & NA & $\mathrm{s}$ \\
\hline t_s_2 & The moment at $\mathrm{t}=\mathrm{t} \_\mathrm{s} \_1+\Delta \mathrm{t} \_\mathrm{s}$. & NA & $\mathrm{s}$ \\
\hline $\mathrm{t} \_\mathrm{s} \_3$ & $\begin{array}{l}\text { The moment at which the cuff pressure } \\
\text { level increases and is higher than the } \\
\text { pressure level of PTC }+\Delta \text { pe. }\end{array}$ & NA & $\mathrm{s}$ \\
\hline t_s_4 & The moment at $\mathrm{t}=\mathrm{t} \_\mathrm{s} \_3+\Delta \mathrm{t} \_\mathrm{s}$. & NA & $\mathrm{s}$ \\
\hline $\mathrm{p}$ & $\begin{array}{l}\text { The pressure level referred as the "current } \\
\text { pressure level" in the method description. }\end{array}$ & NA & $\mathrm{mmHg}$ \\
\hline$\Delta \mathrm{pe}$ & The error tolerance of the cuff pressure. & 2 & $\mathrm{mmHg}$ \\
\hline$\Delta \mathrm{p} 0$ & The pressure decrease factor. & 10 & $\mathrm{mmHg}$ \\
\hline$\Delta \mathrm{p} 1$ & The pressure increase factor & 20 & $\mathrm{mmHg}$ \\
\hline$\Delta \mathrm{pc}$ & The pressure compensation factor & 10 & $\mathrm{mmHg}$ \\
\hline PTL & $\begin{array}{l}\text { The pressure threshold for the "low" } \\
\text { state. }\end{array}$ & 10 (Programmable) & $\mathrm{mmHg}$ \\
\hline PTH & $\begin{array}{l}\text { The pressure threshold for the "high" } \\
\text { state. }\end{array}$ & $\begin{array}{l}150 \\
\text { (Programmable) }\end{array}$ & $\mathrm{mmHg}$ \\
\hline PTC & $\begin{array}{l}\text { The pressure level referred as the "current } \\
\text { pressure threshold" (it can be either TL or } \\
\text { TH). }\end{array}$ & $\begin{array}{l}\text { Please refer to } \mathrm{TL} \\
\text { or } \mathrm{TH} \text {. }\end{array}$ & $\mathrm{mmHg}$ \\
\hline RMax & $\begin{array}{l}\text { The maximum control level of the } \\
\text { regulator. }\end{array}$ & 250 & $\mathrm{mmHg}$ \\
\hline RMin & $\begin{array}{l}\text { The minimum control level of the } \\
\text { regulator. }\end{array}$ & 0 & $\mathrm{mmHg}$ \\
\hline$P_{\text {error }}$ & The pressure error defined in (6) & NA & $\mathrm{mmHg}$ \\
\hline$t_{r d}$ & The response delay defined in (7) & NA & $\mathrm{s}$ \\
\hline
\end{tabular}




\section{Introduction}

Control of blood flow in the brain is dominated by the mechanisms of cerebral autoregulation [1] and reactivity to arterial $\mathrm{CO} 2-$ level $(\mathrm{PaCO} 2)$ changes [2]. The former maintains cerebral blood flow (CBF) relatively constant despite changes in mean arterial blood pressure (ABP) and the latter reflects the strong effects that changes in $\mathrm{PaCO}_{2}$ can have on CBF. Many previous studies using system identification techniques to investigate $\mathrm{CBF}$ regulatory mechanisms were based on spontaneous fluctuations of $\mathrm{ABP}$ (as input) and $\mathrm{CBF}$ (as output) to extract information about the dynamic properties of cerebral autoregulation in the frequency or time-domain $[3,4,5]$, and such modeling has also been extended to $\mathrm{CO} 2$ reactivity $[3,5]$. Despite the many advantages of using spontaneous physiological fluctuations in the input and output signals, this approach has several limitations, chiefly the reliability of model based estimates due to poor signal-to-noise ratio and narrow band spectral distributions. To overcome these problems, several different manoeuvres have been proposed, such as the release of compressed thigh cuffs, tilting, changes in posture, hand grip, Valsalva and synchronised breathing [1]. Many of these manoeuvres though require subject cooperation and in general do not provide the continuous stationary changes required by most system identification approaches. Therefore, the need exist for techniques that can induce changes in $\mathrm{ABP}$ and $\mathrm{PaCO} 2$, independent of subject cooperation and can also allow precise timing and amplitude of stimulation. Hypercapnia, induced by for example breathing of a 5\% $\mathrm{CO} 2$ in air mixture, is also well known to induce temporary impairment of autoregulation [1] and this has been extensively used when assessing methods to measure autoregulation [1, $4,6]$.

In 2007 Aaslid et al [7] reported the combined use of three Hokanson ${ }^{1}$ units (i.e., a controller, an air source unit and a timer) to drive bilateral thigh cuffs on and off at a constant frequency of $0.05 \mathrm{~Hz}$. Their system did not allow changes in frequency or other controls, and also did not incorporate the ability to assess reactivity to $\mathrm{CO}_{2}$ changes. Moreover, information about the rise time of the pressure changes and their stability inside the cuff was not provided either.

${ }^{1}$ D. E. Hokanson, Inc., Bellevue, 12840 NE 21st Place, WA 98005 USA 
A novel design/implementation approach is introduced in this study for a system to assess autoregulation using inflatable cuffs around the thighs, with its pressure management based on closed-loop adaptive feedback control, with simultaneous control of inspired $\mathrm{CO} 2$ levels. The key system operation is to impose changes in ABP through inflation of cuffs, and allow arbitrary changes in pressure (e.g. periodic, non-periodic or pseudo-random) with pressure levels pre-programmed and sustained over prolonged intervals. The system features include the novel design and implementation of the adaptive feedback control mechanism, which contributes to a fast rise time and reduces cuff pressure errors during extended inflations.

Statistical results from the evaluations suggest that the adaptive system is superior to the simple threshold system, in terms of system performances on pressure error and response delay. The results show that the implemented adaptive system can effectively reduce the pressure fluctuations caused for example by air leaking, mechanical compliance in the system, or patient movement.

\section{Methods}

\subsection{System specification}

The main system requirements are: a) flexibility in operation (e.g. cuff control and $\mathrm{CO}_{2}$ delivery controlled separately or combined); b) pre-programmed arbitrary sequences for $\mathrm{ABP}$ and/or $\mathrm{CO}_{2}$ delivery; both amplitude and timing of pressure changes can be programmed; c) fast and accurate pressure control allowing the cuff pressure to change from 10 to $150 \mathrm{mmHg}$ in less than $1.0 \mathrm{~s}$; d) user friendly interface ; e) compliance with strict safety requirements.

\subsection{System design and structure}

The block diagram of the new programmable control system for evaluations of cerebrovascular function is shown in Fig. 1, consisting of three sub-system blocks: a cuff pressure controller, a CO2/air controller and a central controller.

The central controller reads the desired control data (e.g. sequence of sample values for pressure and $\mathrm{CO}_{2}$ level) from a control data file. It compares these data with the measured pressure feedback signals in real-time before sending control 
commands to the other two controllers. The central controller comprises a combination of hardware and software components that include a PC, an USBbased analog and digital I/O module USB-1408FS ${ }^{2}$ and Windows-based control software. This controller provides a user-friendly interface platform, which allows an operator to conveniently select data and modify parameters the system running mode. An adaptive feedback control unit is included in this controller to achieve more accurate pressure level control (Section 2.3 for details).

The cuff pressure controller and the CO2/air controller are two hardware-based control units, which control the cuff pressure and the $\mathrm{CO}_{2}$ inhalation according to the control commands received from the central controller. Several hardwarebased safety measures are included in these two controllers. The cuff pressure controller also forms part of the feedback loop within the adaptive control scheme. The CO2/air controller selects either pure air or air mixed with $\mathrm{CO}_{2}$ (typically 5\% $\mathrm{CO} 2$ in air) as the gas source supplied to the subject/patient, usually via a facemask, and includes electronically controlled valves and safety features.

\subsection{The design and the implementation of adaptive feedback control scheme for the thigh cuff pressure}

As shown in Fig. 2, an adaptive feedback control scheme was implemented to control the cuff pressure. The illustrated control structure is based on a modified version of the parallel scheme for model reference adaptive control (MRAC) systems [8], which consists of an inner loop for control state transition management and an outer loop for control case selections and pressure level evaluation. Following initial tests with a simpler control system, the MRAC approach was selected to ensure compliance with the required specifications and overcome limitations of off-the-shelf controllers and valves which may be subject to potential "dead-zone", backlash and hysteresis effects [9].

The above control model is applied in this study to implement a three-input nonlinear control system, which has a control vector with a generalized denotation as follows:

\footnotetext{
${ }^{2}$ Measurement Computing Corporation, Norton, MA 02766, USA
} 
$[\operatorname{Inp}(\mathrm{t})]^{\mathrm{T}}=[\mathrm{P}(\mathrm{t}), \mathrm{VI}(\mathrm{t}), \mathrm{VD}(\mathrm{t})]$

where $\mathrm{P}(\mathrm{t})$ is the pressure level of the pressure regulator at time $\mathrm{t}$; VI(t) is the inflation valve control input and the $\operatorname{VD}(\mathrm{t})$ is the deflation control input; and the symbol $\mathrm{T}$ denotes the transpose operation. The value of $\mathrm{P}(\mathrm{t})$ could range from the RMin (the minimum regulator pressure) to RMax (the maximum regulator pressure). The valve inputs $\mathrm{VI}(\mathrm{t})$ and $\mathrm{VD}(\mathrm{t})$ can be either 1 (open) or 0 (closed).

Before providing details of the states of the control system, an overview will be given. In order to ensure fast inflation, the "over-boost-and-compensate" technique is employed as illustrated in Fig. 3. During the inflation phase, the pressure regulator (Fig. 2) is turned to the maximum level (Rmax) instead of the target pressure (PTH) in order to accelerate inflation, and the inflation valve is opened. When the cuff pressure reaches the PTH, the inflation valve closes, and control signal of the regulator is changed to the minimum level (RMin) to prevent overshoot of the cuff pressure before being set to the PTH. The system then enters the pressure holding phase, where the regulator aims to keep the pressure within a narrow tolerance range of the target. When cuff pressure falls below the range (e.g. due to leakage), the inflation valve opens and a control level higher than the PTH is applied to the regulator in order to increase the cuff pressure. This holding process continues (with a linearly increased control level) until the cuff pressure is brought back to the PTH. When the cuff pressure is above the tolerance range (e.g. due to the patient moving and shifting more weight onto the cuffs), the same holding process will be carried out except that a low control signal is applied to the regulator to bring down the cuff pressure. For deflation of the cuffs in accordance with the drop in target pressure at the end of the holding state, the deflation valve opens to ambient air (a fast, low-resistance pathway) and the deflation valve closes when the desired pressure is reached. No "over-boost-andcompensate" approach is needed or employed during this phase.

The above 3-phase scheme was implemented using an "adaptive inverse approach" [9] with three control states are defined following (1):

$$
\operatorname{Inp}(t)=\left\{\begin{array}{lr}
\operatorname{Inp}_{10}(t), & \text { transient state: } S \_10(\text { cuff deflation }) \\
\operatorname{Inp}_{01}(t), & \text { transient state: } S \_01(\text { cuff inflation }) \\
\operatorname{Inp}_{\text {hd }}(t), & \text { holding state: } S \_ \text {hd }(\text { stable pressure desired })
\end{array}\right.
$$


Each of these three control states further contains several control cases, as shown in (3)-(5). The details of the control cases and the parameters used in these equations are provided in Table 1.

$$
\begin{gathered}
{\left[\operatorname{Inp}_{10}(\mathrm{t})\right]^{\mathrm{T}}= \begin{cases}{[\mathrm{PTH}, 0,0],} & \text { Case_0_1 } \\
{[\mathrm{PTL}, 1,1],} & \text { Case_0_2 } \\
{[\mathrm{PTL}, 0,0],} & \text { Case_0_3 }\end{cases} } \\
{\left[\operatorname{Inp}_{01}(\mathrm{t})\right]^{\mathrm{T}}=\left\{\begin{array}{cc}
{[\mathrm{PTL}, 0,0],} & \text { Case_1_1 } \\
{[\mathrm{RMax}, 1,0],} & \text { Case_1_2 } \\
{[\mathrm{RM} i n, 0,0],} & \text { Case_1_3 } \\
{[\mathrm{PTH}+\Delta \mathrm{pc}, 0,0],} & \text { Case_1_4 }
\end{array}\right.}
\end{gathered}
$$

$$
\left[\operatorname{Inp}_{\mathrm{hd}}(\mathrm{t})\right]^{\mathrm{T}}=\left\{\begin{array}{cc}
{[\mathrm{TC}, 0,0],} & \text { Case_h_1 } \\
{[\mathrm{TC}+\Delta \mathrm{p} 1,1,0],} & \text { Case_h_2 } \\
{\left[\mathrm{TC}+\Delta \mathrm{p} 1+20\left(\mathrm{t}-\mathrm{t} \_\mathrm{s} \_2\right), 1,0\right],} & \text { Case_h_3 } \\
{[\mathrm{TC}-\Delta \mathrm{p} 0,1,0],} & \text { Case_h_4 } \\
{\left[\mathrm{TC}-\Delta \mathrm{p} 0-20\left(\mathrm{t}-\mathrm{t} \_\mathrm{s} \_4\right), 1,0\right],} & \text { Case_h_5 }
\end{array}\right.
$$

In Fig.3 a), data recorded from a healthy volunteer are used to illustrate these three control states, whilst the control cases defined in equation (4) are illustrated in the zoomed screen image in Fig. 3 b). The logic chart shown in Fig.4 shows the logical controls in equation (5), which ensures that the impact of every control command is always to diminish the difference between the cuff pressure and the desired pressure. The logic charts for Equations (3) and (4) are similar to Fig.4 but much simpler, which are not illustrated here for simplicity.

The adaptive controller inserts a waiting period of $100 \mathrm{~ms}$ after every pressure change in equation (5), during which no new pressure change is allowed. This allows the relatively slow regulator to catch up on faster pressure control commands. The waiting period also plays a "damping" role to neutralize any potential oscillations of the pressure control.

Two parameters are used to assess performance.

The first one is the pressure error $\mathrm{P}_{\text {error }}$, as defined as: 
$\mathrm{P}_{\text {error }}=\mathrm{P}_{\text {cuff }}-\mathrm{P}_{\text {ideal }}$

where $\mathrm{P}_{\text {cuff }}$ is the cuff pressure and $\mathrm{P}_{\text {ideal }}$ is the ideal pressure signal defined in the control data file.

The second parameter $t_{r d}$ is defined in the time domain as the response delay for pressure edge changes, as in the following equation:

$\mathrm{t}_{\mathrm{rd}}=\mathrm{t}_{\mathrm{ct}}-\mathrm{t}_{\mathrm{it}}$

where $t_{i t}$ is the time moment when the $P_{\text {ideal }}$ changes to the targeted pressure level (i.e. PTH or PTL) and $t_{c t}$ is the moment when the $\mathrm{P}_{\text {cuff }}$ actually reaches this level.

For the purposes of evaluation, the performance of the adaptive controller was compared with an alternative, simple implementation, in which inflation and the holding state was controlled only by step-wise changes in the pressure regulator input. This will be denominated simple threshold control.

\subsection{The safety considerations and safety measures implemented}

The recommended pressure level range from the European Society of Hypertension [10] (originally for the purpose of blood pressure measurement) were used to guide the safety specifications of the new system.

The implemented safety measures can be summarized as follows:

- If power is interrupted, cuffs will deflate and pure air is provided to the face-mask, based on the 'normally open/closed' characteristics of each valve.

- Basic pressure level protection is provided by the safety valve as shown in Fig. 1. This valve automatically opens to release the air if the pressure of the regulator persistently exceeds $200 \mathrm{mmHg}$. This protection is designed to be triggered by prolonged high pressure levels, rather than short transients as may occur during regulator action.

- If any instantaneous pressure at the output of the regulator reaches the 290 $\mathrm{mmHg}$, the system will be forced into the reset state (cuffs are deflated and 
air is provided to the face-mask). A hardware circuit and software functions work in parallel, and both can trigger this reset state.

- The cuff pressure is constantly monitored through the cuff pressure transducer and is adaptively controlled. If, for any reason, the cuff pressure reaches a pre-set threshold (default of $250 \mathrm{mmHg}$ ), the system will deflate the cuff and then force the central controller into a reset state.

- $\mathrm{CO}_{2}$ /air pressure level protection is provided by a safety valve (Fig. 1) connected to the $\mathrm{CO}_{2}$ bottle. This valve automatically opens to release the air if the inspiratory $\mathrm{CO}_{2}$ /air pressure reaches $2.5 \mathrm{cmH}_{2} \mathrm{O}(1.84 \mathrm{mmHg})$.

- The central controller generates a $50 \mathrm{~Hz}$ watchdog clock $(0-5 \mathrm{v}$ square wave) and sends the signal to a hardware monitoring circuit. If the clock signal is interrupted for longer than $160 \mathrm{~ms}$ (e.g. by software error), the system will deflate the cuffs and force the central controller into a reset state.

- The system was tested for electrical safety by independent assessors, according to the IEC 60601-1 standard.

\subsection{Evaluation procedures}

The evaluations in this study are focused on the implementation improvements of the cuff pressure, rather than the physiological effects caused by the pressure changes which have been reported elsewhere [11]. Experiments were carried out to achieve the following objectives: a) to examine the ability of the system to compensate for non-linearity control effects and unpredictable variations of cuff pressure; b) to statistically evaluate the error between the target and cuff pressures; c) to assess the system delay in imposing pressure changes.

The evaluation data were recorded from a healthy volunteer (56-year old male). The cuffs were placed around the thighs of the volunteer and two pre-programmed "ideal" control sequences (sampled at $1 \mathrm{~Hz}$ ) were used to generate dynamic pressure changes. The first was a 'low frequency' square wave signal with its control cycle containing a 29-s "low" pressure state $(10 \mathrm{mmHg})$ followed by a 29s "high" pressure state $(150 \mathrm{mmHg})$. The second was a 'high frequency' sequence 
containing a 10-s "low" state followed by a 10-s "high" state. The lengths of the two sequences were $1693 \mathrm{~s}$ and $1290 \mathrm{~s}$, respectively. These two sequences were used to test the impact of the duration of holding states on the pressure error $\mathrm{P}_{\text {error }}$.

Each of the two target signals was then used to control the cuffs, using both the adaptive and the simple pressure control schemes.

Institutional ethics approval was obtained to conduct above experiments and written informed consent was given by the volunteer before the experiments were performed.

\subsection{Data acquisition}

Analogue cuff pressure signal was obtained from the pressure transducer shown in Fig. 1and the target signal was obtained from the input to the output of the central controller (USB-1408FS). An A/D unit based on a DT-301 data acquisition board ${ }^{3}$ was used to acquire above-mentioned analogue signals. Unless otherwise stated, all the data acquisitions were carried out using a system sampling frequency of $500 \mathrm{~Hz}$ and then re-sampled at $50 \mathrm{~Hz}$. Matlab ${ }^{4}$-based programs were written and used to analyze the acquired data for all the evaluation purposes in this study.

\section{Results}

Cuff pressure data corresponding to a typical step with and without adaptive control and after signal alignment are illustrated in Fig.5, together with the corresponding ideal pressure signal.

Table 2 and Fig.6 present the distributions of $\mathrm{P}_{\text {error }}$, for the four recordings, showing a substantial reduction of the pressure error when the adaptive system is used, in comparison with the simple threshold case, for both target sequences.

Table 2 also provides the error breakdown for both the high- and the low-pressure holding states (see Fig. 3a). The pressure error for the low state (S_hd(0)) did not show significant differences between the two system configurations, but in

\footnotetext{
3 Data Translation GmbH, Im Weilerlen 10, 74321 Bietigheim-Bissingen, Germany.

${ }^{4}$ MathWorks, 3 Apple Hill Drive, Natick, MA, USA.
} 
holding high state (S_hd(1)) there was a dramatic reduction in error due to the use of adaptive feedback instead of the simple threshold system. The use of adaptive feedback also halved the time delay for the rising edge of the cuff pressure, but had no significant effect on the falling edge of the pressure signal (Table 2). The results for the "holding-high" state show that the adaptive system outperformed the simple threshold system with significantly improved means and standard deviations. The error improvements can be estimated using the percentage of the mean difference such as $(\mathrm{M} 1-\mathrm{M} 2) / \mathrm{M} 1=99.57 \%$ and $(\mathrm{M} 3-\mathrm{M} 4) / \mathrm{M} 3=98.02 \%$, corresponding to the low- and high-frequency control signal cases, respectively.

\section{Discussion}

From the set of results it is clear that the adaptive feedback controller implemented provided much more accurate and fast pressure changes than the more straightforward simple feedback threshold method. The latter led to a pressure decline during the holding phase that could reach $15 \%$ in our experiments. This lower value at the end of the high-pressure phase probably explains the faster return to the low-pressure state noted in Table 2, and is more pronounced for the longer holding phase. The exact reasons that the 'high' pressure is not maintained by the simple threshold method are not entirely clear, but are possibly a combination of air leaks, compliance in the system (including cuffs), and the resulting uneven dynamic pressure distributions.

It can also be seen from the results that the pulse repetition frequency of the control signal has an effect on the error distributions. For example, when a lower frequency was applied the error distribution deteriorated for the simple threshold system but the distribution improved for the adaptive system. Further investigations reveal that both the deterioration and the improvement were mainly due to the pressure data obtained from the longer "high state" duration, during which the "pressure drifting effect" became deteriorated with the simple controller.

To effectively evaluate the performances of the two systems, periodical control signals (i.e., control signals with a constant pulse length) were used in the evaluations in this study. In separate studies on blood pressure variations resulting 
from the application of the thigh-cuffs [11], pseudo-random control sequences were used, which confirmed the suitability of the system for clinical and physiological studies.

\section{Conclusions and Future Work}

A programmable adaptive feedback control system for cerebral autoregulatory evaluations was designed and developed in this study. The system was implemented to flexibly change the pressure level of a pair of thigh cuffs and the supply of $\mathrm{CO} 2$, which could be used as programmable stimuli in studies of autorgulation. Adaptive feedback control theory was applied to alter and maintain the pressure level of the thigh cuffs, using the arbitrary logical sequences stored in control files as the "ideal" control inputs. A numbers of safety measures were included to insure that the pressure and $\mathrm{CO} 2$ are safely supplied.

Purposely planned experiments were carried out in this study to compare the pressure control performances of the implemented adaptive system against those of a "simple threshold" system based on a straightforward threshold control method. The two systems were tested on a healthy volunteer to evaluate their performances as regards pressure control and delay in changing pressure. The evaluation results demonstrated that the adaptive system significantly improved the pressure error distributions with much ameliorated means and variances in the errors. They also show that the adaptive system outperformed the simple threshold system with significantly improved response time for the pressure changes containing rising edges. Extensive subsequent studies on human volunteers have confirmed the effectiveness of the design and implementation.

\section{Acknowledgement}

The research described here has been supported by the UK EPSRC grant No. EP/G008787/1.

The authors sincerely thank Mike Squires and Milan Drca, for their help implementing the pressure and $\mathrm{CO}_{2}$ controllers. 


\section{References}

1. Panerai, R.B. (1998) Assessment of cerebral pressure autoregulation in humans - a review of measurement methods. Physiological Measurement, 19(3):305-338.

2. Poulin, M.J., Liang, P.J., \& Robbins, P.A. (1996) Dynamics of the cerebral blood flow response to step changes in end-tidal PCO2 and PO2 in humans. Journal of Applied Physiology, 81(3):1084-1095.

3. Panerai, R.B., Simpson, D.M., Deverson, S.T., Mahoney, P., Hayes, P., \& Evans, D.H. (2000) Multivariate dynamic analysis of cerebral blood flow regulation in humans. IEEE Transactions on Biomedical Engineering, 47(3):419-423.

4. Simpson, D.M., Panerai, R.B., Evans, D.H., \& Naylor, A.R. (2001) A parametric approach to measuring cerebral blood flow autoregulation from spontaneous variations in blood pressure. Annals of Biomedical Engineering, 29(1):18-25.

5. Mitsis, G.D., Poulin, M.J., Robbins, P.A., \& Marmarelis, V.Z. (2004) Nonlinear modeling of the dynamic effects of arterial pressure and $\mathrm{CO} 2$ variations on cerebral blood flow in healthy humans. IEEE Transactions on Biomedical Engineering, 51(11):1932-1943.

6. Liu, J., Simpson, D.M., Yan, J., \& Allen, R. (2010) Tracking time-varying cerebral autoregulation in response to changes in respiratory $\mathrm{PaCO} 2$. Physiological Measurement, 31, 1291-1307.

7. Aaslid R, Blaha M, Sviri G, Douville CM, Newell DW (2007) Asymmetric dynamic cerebral autoregulatory response to cyclic stimuli. Stroke. 38(5):1465-1469.

8. Sastry S. and Bodson M. (1989) Adaptive control: stability, convergence, and robustness, Prentice Hall, Englewood Cliffs, New Jersey.

9. Tao G. (1999) Adaptive inverse for actuator compensation. In: Feng G. and Lozano R. (eds) Adaptive control systems. Newnes, Oxford, pp 260286.

10. O’Brien E, Asmar R, Beilin L, Imai Y, Mallion J, Mancia G, Mengden T, Myers M, Padfield P, Palatini P, Parati G, Pickering T, Redon J, Staessen J, Stergiou G and Verdecchia P, on behalf of the European Society of Hypertension Working Group on Blood Pressure Monitoring (2003) 
European Society of Hypertension recommendations for conventional, ambulatory and home blood pressure measurement, Journal of Hypertension, 21(5):821-848.

11. Katsogridakis, E., Bush, G., Fan, L., Birch, A.A., Simpson, D.M., Allen, R., Potter, J.F., \& Panerai, R.B. 2012. Random perturbations of arterial blood pressure for the assessment of dynamic cerebral autoregulation. Physiological Measurement, 33(2):103-116.

Table 1 Control states, control cases, conditions and actions (please refer to the Glossary of Terms for the descriptions of the symbols)

\begin{tabular}{|c|c|c|c|c|}
\hline Control State & Control Case & Conditions & Control Vector & Control Actions \\
\hline \multirow{3}{*}{$\begin{array}{l}\text { S_01 state } \\
\text { (cuff } \\
\text { inflation) }\end{array}$} & Case_0_1 & $\mathrm{t}<\mathrm{t} \_0$ & {$[\mathrm{PTH}, 0,0]$} & There is no valve action before $\mathrm{t}=\mathrm{t} \_0$. \\
\hline & Case_0_2 & $\begin{array}{l}\mathrm{t} \geq \mathrm{t} \_0 \text { and } \\
\mathrm{p}>\mathrm{PTL}\end{array}$ & {$[\mathrm{PTL}, 1,1]$} & $\begin{array}{l}\text { Both the inflation and deflation valves } \\
\text { are open to reduce both the cuff pressure } \\
\text { and the regulator pressure. }\end{array}$ \\
\hline & Case_0_3 & $\begin{array}{l}\mathrm{t} \geq \mathrm{t} \_0 \text { and } \\
\mathrm{p} \leq \mathrm{PTL}\end{array}$ & {$[$ PTL, 0, 0] } & $\begin{array}{l}\text { The inflation and the deflation valves are } \\
\text { closed to maintain the cuff pressure. }\end{array}$ \\
\hline \multirow{4}{*}{$\begin{array}{l}\text { S_10 state } \\
\text { (cuff } \\
\text { deflation) }\end{array}$} & Case_1_1 & $\mathrm{t}<\mathrm{t} \_1$ & {$[$ PTL, 0, 0] } & There is no valve action before $\mathrm{t}=\mathrm{t} \_1$. \\
\hline & Case_1_2 & $\begin{array}{l}\mathrm{t} \geq \mathrm{t} \_1 \text { and } \\
\mathrm{p}<\mathrm{PTH}\end{array}$ & {$[\mathrm{RMax}, 1,0]$} & $\begin{array}{l}\text { Regulator pressure is changed to high } \\
\text { and the inflation valve is open. }\end{array}$ \\
\hline & Case_1_3 & $\begin{array}{l}\mathrm{t} \geq \mathrm{t} \_1 \_1 \text { and } \\
\mathrm{t}<\mathrm{t} \_1 \_2 \text { and } \\
\mathrm{p} \geq \mathrm{PTH}\end{array}$ & [RMin, 0, 0] & $\begin{array}{l}\text { Regulator pressure is changed to low } \\
\text { during a "cooling period" (default = } \\
0.4 \mathrm{~s} \text { ), to compensate the delayed non- } \\
\text { linear reaction from the regulator. }\end{array}$ \\
\hline & Case_1_4 & $\begin{array}{l}\mathrm{t} \geq \mathrm{t} \_1 \_2 \text { and } \\
\mathrm{p} \approx \mathrm{TH}\end{array}$ & {$[\mathrm{PTH}, 0,0]$} & $\begin{array}{l}\text { The pressure control is switched back to } \\
\mathrm{TH} \text {, so that the regulator can quickly } \\
\text { response to any adaptive controls in the } \\
\text { following maintenance state. }\end{array}$ \\
\hline \multirow{5}{*}{$\begin{array}{l}\text { Holding states } \\
\text { including: } \\
\text { S_hd(0) state } \\
\text { (holding low) } \\
\text { and S_hd(1) } \\
\text { state (holding } \\
\text { high) }\end{array}$} & Case_h_1 & $\mid$ p-PTC $\mid<\Delta$ pe & {$[\mathrm{PTC}, 0,0]$} & $\begin{array}{l}\text { There is no action when the pressure } \\
\text { error can be tolerated. }\end{array}$ \\
\hline & Case_h_2 & $\begin{array}{l}\mathrm{t} \geq \mathrm{t} \_\mathrm{s} \_1 \text { and } \\
\mathrm{t}<\mathrm{t} \_\mathrm{s} \_2 \text { and } \\
\mathrm{p}<(\mathrm{PTC}-\Delta \mathrm{pe})\end{array}$ & {$[\mathrm{PTC}+\Delta \mathrm{p} 1,1,0]$} & $\begin{array}{l}\text { The regulator pressure is increased and } \\
\text { the increased pressure is passed to the } \\
\text { cuff through the inflation valve that is } \\
\text { open. }\end{array}$ \\
\hline & Case_h_3 & $\begin{array}{c}\mathrm{t} \geq \mathrm{t} \_\mathrm{s} \_2 \text { and } \\
\mathrm{p}<(\mathrm{PTC}-\Delta \mathrm{pe})\end{array}$ & $\begin{array}{l}{[\mathrm{PTC}+\Delta \mathrm{p} 1+20(\mathrm{t}-} \\
\left.\left.\mathrm{t} \_\mathrm{s} \_2\right), 1,0\right]\end{array}$ & $\begin{array}{l}\text { The regulator pressure increases linearly, } \\
\text { to compensate the dropping cuff } \\
\text { pressure. The pressure level is capped by } \\
\text { RMax. }\end{array}$ \\
\hline & Case_h_4 & $\begin{array}{l}\mathrm{t} \geq \mathrm{t} \text { _s_3 and } \\
\mathrm{t}<\mathrm{t} \text { _s_4 and } \\
\mathrm{p}>(\mathrm{PTC}+\Delta \mathrm{pe})\end{array}$ & {$[\mathrm{PTC}-\Delta \mathrm{p} 0,1,0]$} & $\begin{array}{l}\text { The regulator pressure is decreased and } \\
\text { the decreased pressure level is passed to } \\
\text { the cuff through the inflation valve that is } \\
\text { open. }\end{array}$ \\
\hline & Case_h_5 & $\begin{array}{c}\mathrm{t} \geq \mathrm{t} \_\mathrm{s} \_4 \text { and } \\
\mathrm{p}>(\mathrm{PTC}+\Delta \mathrm{pe})\end{array}$ & $\begin{array}{l}{[\mathrm{PTC}-\Delta \mathrm{p} 0-20(\mathrm{t}-} \\
\left.\left.\mathrm{t} \_\mathrm{s} \_4\right), 1,0\right]\end{array}$ & $\begin{array}{l}\text { The regulator pressure decreases linearly, } \\
\text { to compensate the rising cuff pressure. } \\
\text { The pressure level is capped by RMin. }\end{array}$ \\
\hline
\end{tabular}


Table 2 The means and standard deviations of the pressure error and the response delay in four recordings

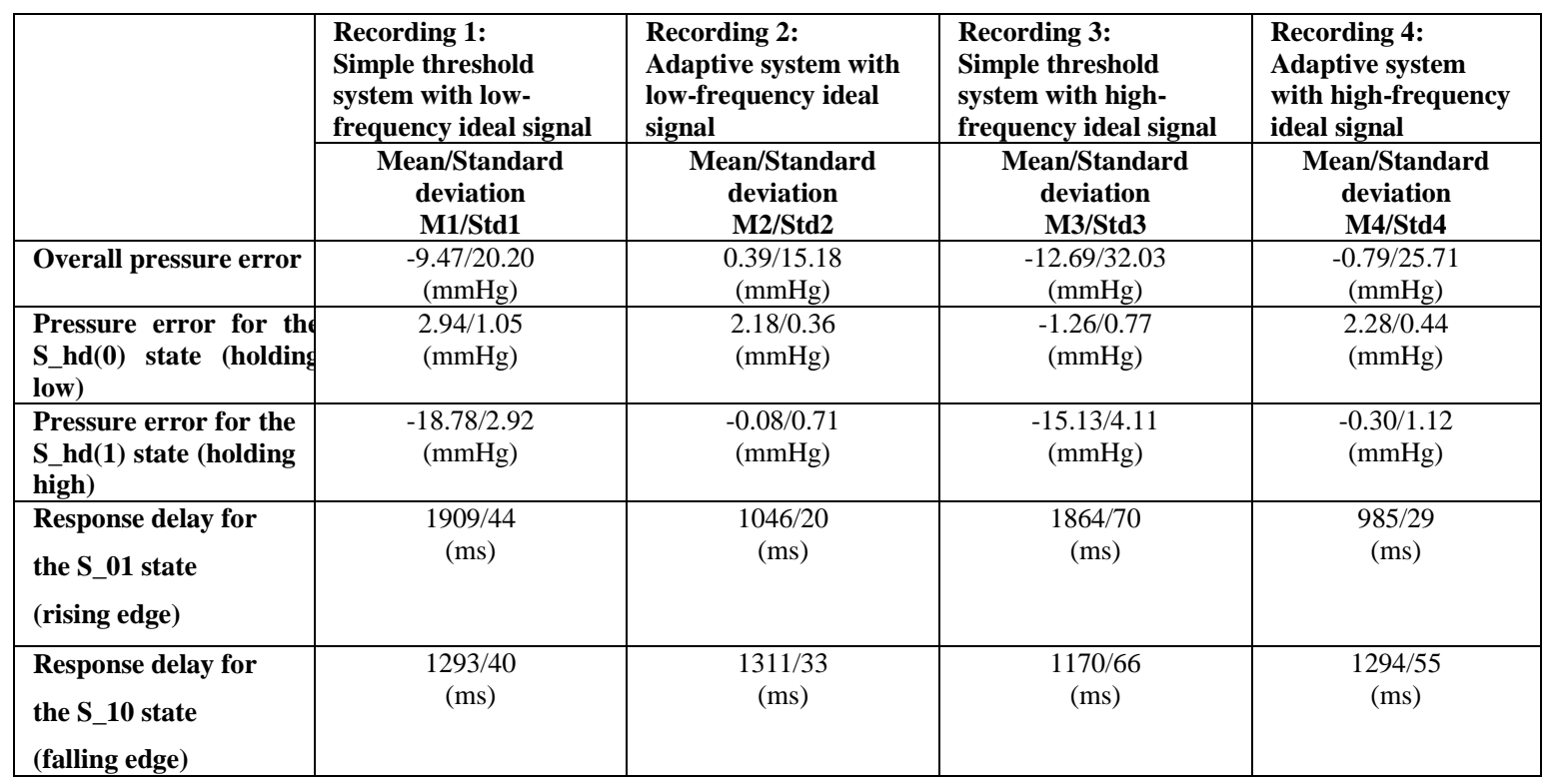

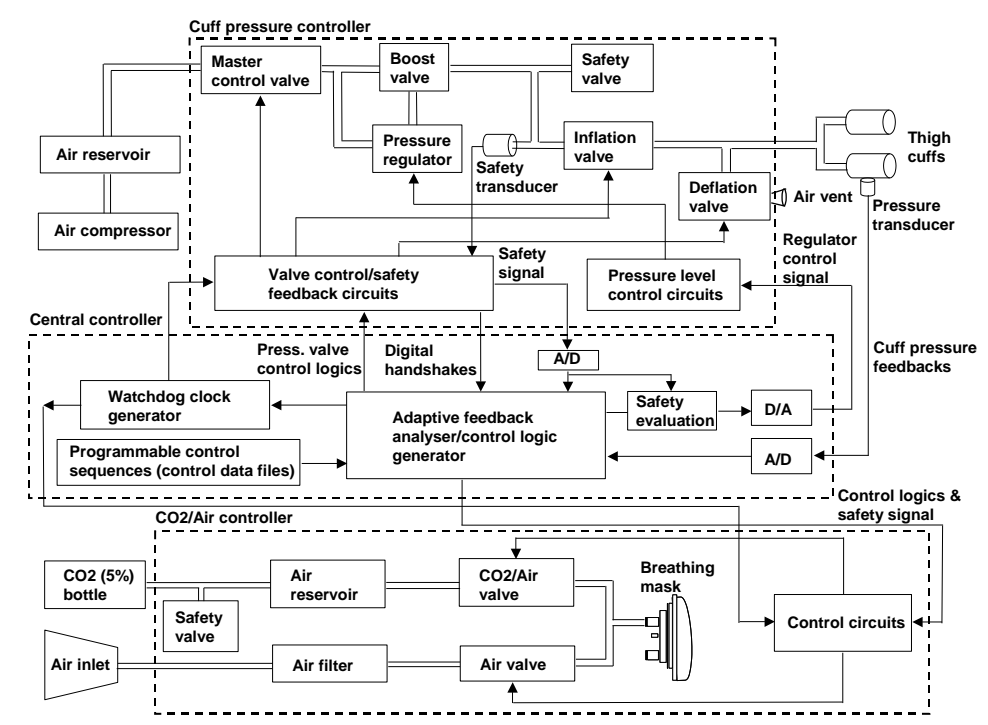

Fig.1 The block diagram of the programmable adaptive feedback control system 


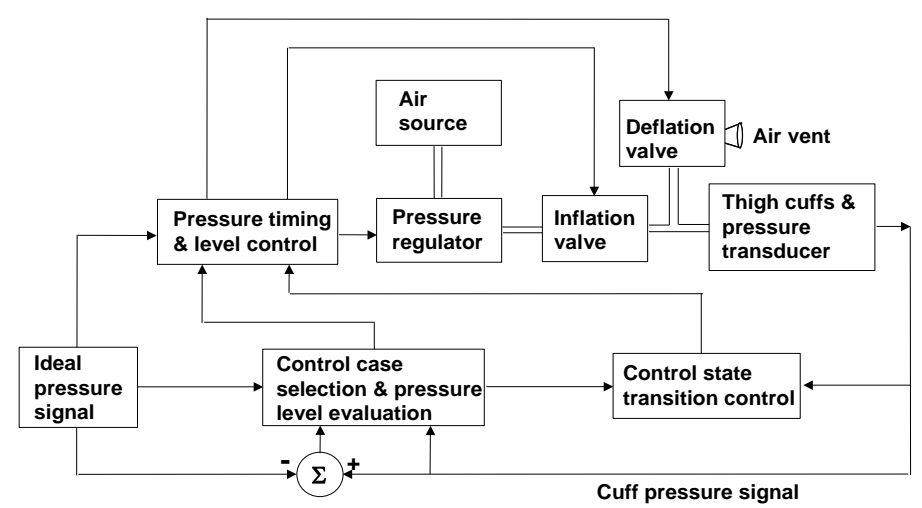

Fig.2 The block-diagram of the adaptive feedback control scheme (cuff pressure control)

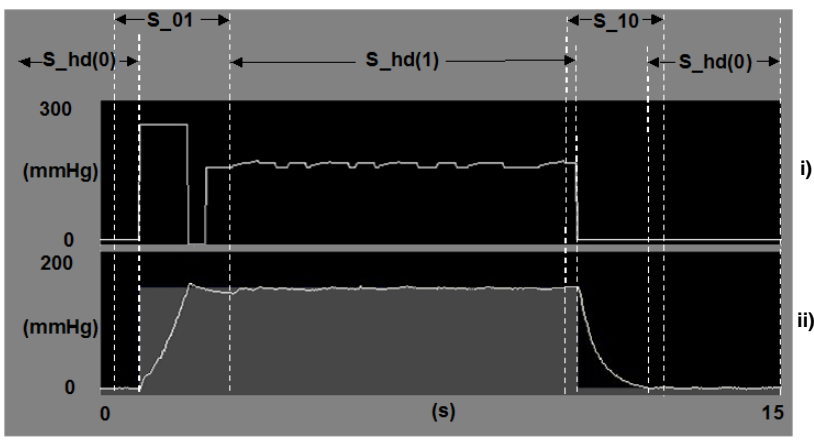

a)

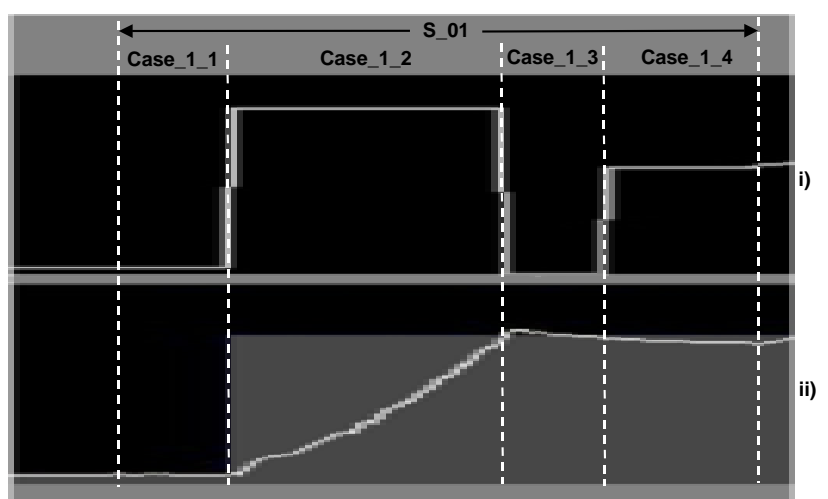

b)

Fig.3 The illustration of control states and control cases using data recorded from a healthy volunteer. a) The control states are shown as follows (some of the states are overlapped with adjacent states): $S \_01$ and $S \_10$ denote the cuff inflation and the cuff deflation states; S_hd(0) and S_hd(1) represent the pressure holding states for low and high pressure levels. The control signal of the regulator is shown in the upper image $i$ ). The recorded cuff pressure signal (white line) and the ideal cuff pressure (grey-colored areas) are displayed in the lower image ii). b) This is a zoomed version of the state S_01 that has been illustrated in a), containing the four control cases defined as Case_1_1 to Case_1_4 in equation (4). 


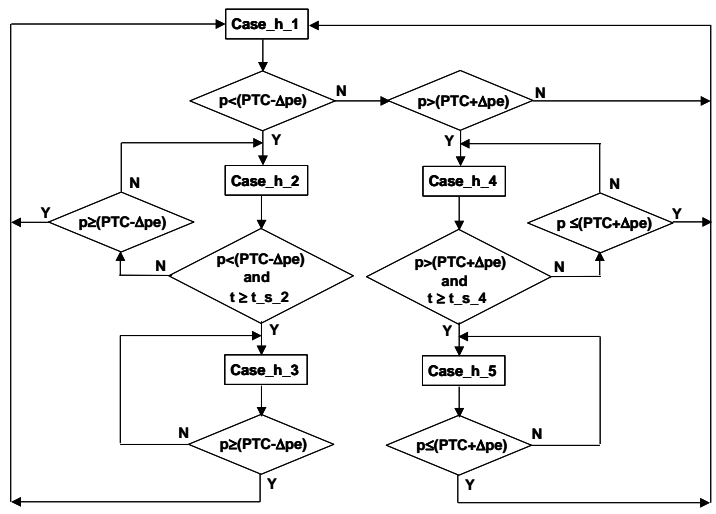

Fig.4 The logical chart of the control cases described in equation (5). Please refer to Tables 1 for details of the control cases and control parameters.

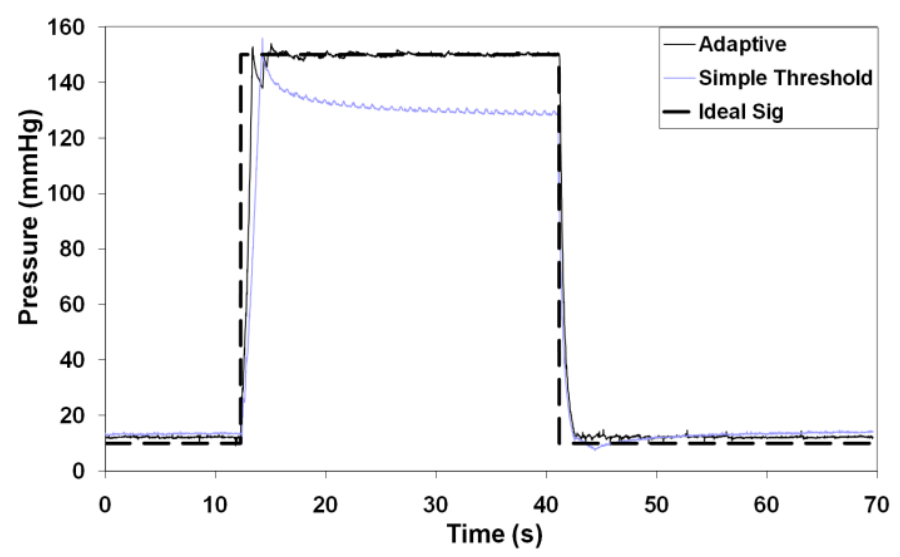

Fig.5 A typical example to compare performances of the cuff pressure control between the adaptive and the simple threshold systems: the resulted cuff pressure from the adaptive control system was much closer to the ideal (target) signal, with a faster rise-time and without the downward drift. These data were obtained from Experiments 1 (simple threshold system driven by the low-frequency ideal signal) and 3 (adaptive system driven by the low-frequency ideal signal)) 


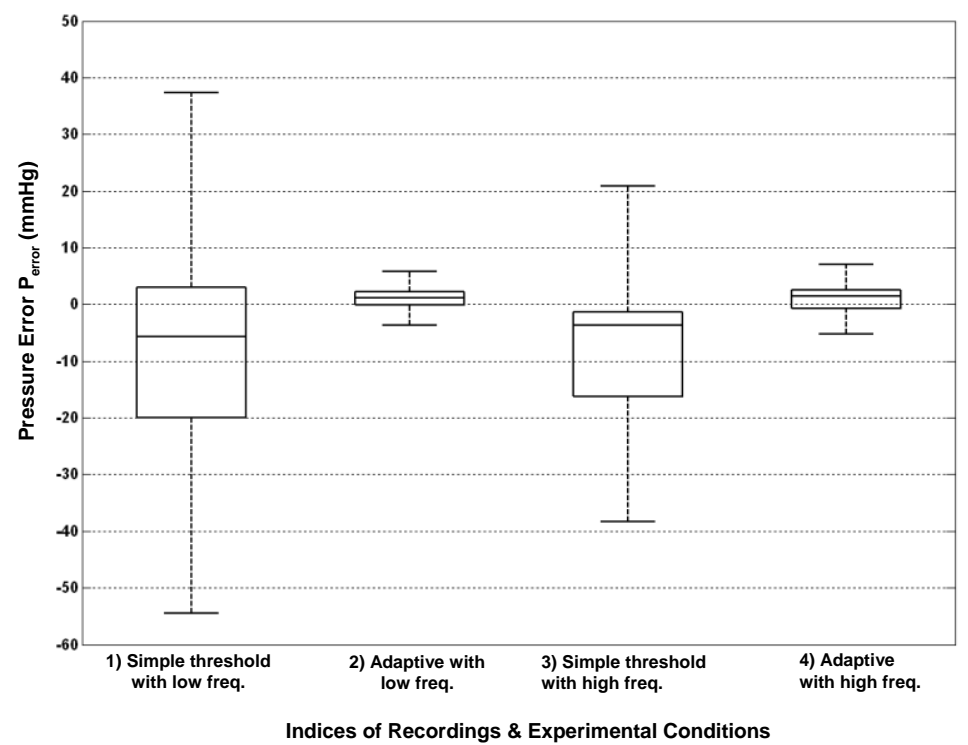

Fig.6 The distribution of cuff pressure error $P_{\text {error }}$ for all the four recordings, showing quartiles, median and minimum and maximum values. Details of the experimental conditions for the four recordings are as follows: 1) simple threshold system driven by the low-frequency target signal (data length: 1693s); 2) adaptive system driven by the lowfrequency target signal (data length: 1693s); 3) simple threshold system driven by the highfrequency target signal (data length: 1290s); 4) adaptive system driven by the high-frequency target signal (data length: 1290s). Improved performance is clearly evident. 